\title{
BARRIERS HUBUNGAN KOMUNIKASI ANTAR BUDAYA WARGA MUSLIM DAN HINDU DALAM UPACARA PUJAWALI DAN PERANG TOPAT DI DAERAH LINGSAR, LOMBOK BARAT, NUSA TENGGARA BARAT
}

\author{
Muhammad Fathoni ${ }^{1}$, Andrik Purwasito' ${ }^{2}$, Mahendra Wijaya ${ }^{3}$ \\ 1,2,3)Program Studi Ilmu Komunikasi \\ Pascasarjana UNS \\ Jln. Ir. Sutami Kentingan Surakarta 57126 \\ email: ujungtinta@gmail.com / cp. $081917020050^{1}$
}

\begin{abstract}
ABSTRAK
Penelitian ini bertujuan menganalisis hambatan hubungan antar budaya warga Muslim dan Hindu pada upacara Pujawali dan Perang Topat di Lingsar, Lombok Barat, Propinsi Nusa Tenggara Barat melalui perasangaka, stereotip, dan etnosentris. Komponen tersebut terbangun dalam komunikasi antar budaya, sehingga membentuk barriers pada warga Muslim dan Hindu di Lingsar. Penelitian ini menggunakan metode deskriptif kualitatif dengan pendekatan etnografi yaitu pendekatan untuk mengurai dan mendeskripsikan hambatan komunikasi antar budaya Pujawali dan Perang Topat dari sudut pandang warga pemilik budaya di Lingsar. Teknik pengumpulan data penelitian ini menggunakan observasi partisipan dan wawancara mendalam. Pengambilan sampel informan menggunakan Purposive sampling. Proses pengumpulan data dengan teknik snowball sampling/chain sampling sebanyak 6 orang informan.

Hasil yang ditemukan adanya sekat komunikasi yang menghambat hubungan warga Muslim dan warga Hindu saat upacara Pujawali dan Perang Topat di Lingsar. Sekat komunikasi tersebut disebabkan oleh perbedaan keyakinan yang dianut antara warga Muslim dan Hindu, terdapat juga masalah kepemilikan Pura dan konflik pemuda sebelum terjadinya upacara Pujawali dan Perang Topat sehingga menyebabkan prasangka, etnosentris dan stereotip.
\end{abstract}

Kata Kunci: Barriers, Hubungan, Komunikasi Antarbudaya, Pujawali dan Perang Topat, Ethnografi.

\section{A. PENDAHULUAN}

Indonesia merupakan negara heterogen yang terdiri dari berbagai macam suku, ras, budaya, dan agama. Keberagaman inilah yang menjadi indikasi atau sebuah karakteristik Indonesia yang begitu plural di era global ini sehingga tak bisa dipungkiri, pluralitas agama ini memiliki potensi dan peran sangat besar dalam proses integrasi dan pembangunan Indonesia. Realitas ini didasarkan pada ajaran agama yang mewajibkan umatnya untuk saling kenal, mencintai sesama dan hidup rukun. Tak terkecuali, Muslim dalam al-Qur'ân surat (Al-Hujurât: 13) yang mengajarkan :

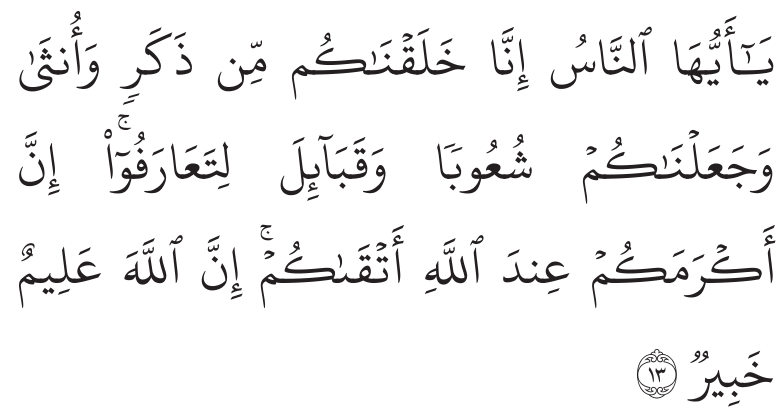

Hai manusia, Sesungguhnya Kami menciptakan kamu dari seorang laki-laki dan seorang perempuan dan menjadikan kamu berbangsa-bangsa dan bersukusuku supaya kamu saling kenal-mengenal. Sesungguhnya orang yang paling mulia diantara kamu disisi Allah ialah orang yang paling taqwa diantara kamu. Sesungguhnya 
Allah Maha mengetahui lagi Maha Mengenal. (Al-Qur'ân surat Al-Hujurât: 13).

$\mathrm{Hal}$ ini terlihat dalam kerukunan warga Muslim dan Hindu sangat terjaga khususnya pada saat upacara Puja Wali dan Perang Topat yang ada di Lingsar. Upacara Pujawali dan Perang Topat adalah upacara yang diadakan sekali setahun menurut penaggalan Sasak dan penaggalan Hindu. Upacara ini adalah sebagai tanda sukur terhadap Tuhan atas hasil pertanian bagi umat Muslim, serta bagi umat Hindu adalah tanda sukur terhadap sang Hiang Widhi agar rizkinya jatuh seperti hujan (Mustain dan Umam, 2005: 228).

Upacara Pujawali dan Perang Topat juga sebuah budaya luhur yang dimiliki oleh masyarakat Indonesia yang tentunya mewakili nilai-nilai yang berasal dari budi pekerti luhur masyarakat setempat. Kelangsungan dan kelancaran upacara ini tidak terlepas dari komunikasi yang didasarkan atas nilai luhur budaya lokal umat beragama. Sehingga, dalam upacara tersebut terbentuk hibungan baik antara warga Muslim dan Hindu.

Perang Topat berasal dari kata Perang dan Topat (ketupat), pada dasarnya upacara ini merupakan saling lempar dengan menggunakan Topat yang dilakukan oleh Muslim dan Hindu di Lombok. Rangkaian dari upacara-upacara ini adalah salah satu cara untuk memperingati atau mengenang Syekh K.H Abdul Malik salah seorang penyiar agama Islam di Pulau Lombok, Lingsar, Lombok Barat tempat diadakannya Perang Topat. Syekh K.H Abdul Malik dengan dua orang saudaranya yaitu K.H Abdul Rouf dan Hj. Raden Ayu Dewi Anjani datang kedaerah tersebut. Lingsar yang tandus pun berubah menjadi daerah yang makmur.

Upacara Perang Topat diadakan pada malam bulan purnama tanggal 15 bulan Comariah, sasi kapitu (bulan ketujuh) menurut kalender Sasak. Rangkaianrangkaian upacara Perang Topat yaitu seperti khaul (sikir nyeribu), geliningan kaok, perang topat dan beteteh.
Nyikir Nyeribuk (khaul) dilakukan tempat persinggahan dari Datu Sumilir dengan membaca solawat, membaca Al-Qur'an, dan berdo'a dilakukan oleh masyarakat Desa Lingsar yang dipimpin oleh Tuan Guru atau Kiai. Khaul ini juga untuk memohon kepada Tuhan agar upacara Pujawali dan Perang Topat supaya bisa berjalan lancar.

Ngeliningan kaok atau mengarak Kerbau dilakuakan oleh warga Muslim dan Hindu dengan berbaris rapi dan teratur. Barisan-barisan diisi oleh masing-masing peran yang berbeda, ada yang barisan yang membawa momot, kebon odeq, lamak dan bunga setaman.

Beteteh atau membuang merupakan rangkaian upacara Pujawali dan Perang Topat yang terakhir. Rangkaian ini adalah upacara untuk mengbuang peralatan yang telah dipakai dalam upacara Pujawali dan Perang Topat, beteteh bermakna untuk membuang sial atau kejelekan-kejelekan selama melakukan prosesi ini.

Upacara Pujawali berasal dari kata pujik, puji (mendoakan, memuliakan) dan wali yang artinya Wali atau wakil Tuhan. Acara Pujawali sebenarnya adalah sebuah upacara yang terdiri dari beberapa rangakaian yang diadakan untuk rasa syukur dan sekligus memperingati hari ulang tahun Pura dan Wali yang turun di Lingsar sehingga dengan rasa sukur ini, diharapkan agar tahun-tahun ini dapat bertambah dan melimpahnya rizky bagi umat Muslim dan Hindu.

Bagi umat Hindu ada beberapa rangkaian upacara Pujawali yaitu Odalan (ulang tahun Pure), mendak (penjemputan Sang Batara) dan makemit (menginap di Pura) yang dilaksanakan pada purnama sasih ke pitu pada penanggalan Hindu. Tradisi ini menjadi sebuah warisan budaya yang unik karena menyamakan persepsi antara dua orang yang berbeda atau kelompok masyarakat Muslim dan Hindu yang berbeda latar belakang budaya bukanlah hal mudah. Pelaksanaan suatu tradisi secara bersamaan oleh kelompok masyarakat yang berbeda agama biasanya sulit terjadi tanpa adanya komunikasi yang baik antar kedua kelompok tersebut. 
Tetapi dalam sebuah hubungan antar budaya tidak terlepas dari perbedaanperbedaan yang menjadi dinamika antara warga Muslim dan Hindu. Hal tersebut tentu saja menjadi sekat yang mengganggu komunikasi saat berjalannya upacara Pujawali dan Perang Topat.

Komunikasi merupakan hal yang dasar dalam interaksi primer, bagi warga Muslim dan Hindu kelancarannya menjadi suatu hal yang urgen dalam mensukseskan setiap prosesi dari rangkaian upacara tersebut. Sehingga penelitian ini akan membahas tentang bagaimana barriers komunikasi warga Muslim dan Hindu dalam upacara Pujawali dan Perang Topat.

\section{B. METODE}

Penelitian ini dilakukan di daerah Lingsar kabupaten Lombok Barat, Nusa Tenggara Barat karena lokasi tersebut memiliki budaya yang berbeda dari tempat-tempat lain. Di sana menjadi tempat pertemua dua agama dalam beribadah karena terdapat Pura yang dianggap keramat bagi Muslim dan Hindu. Pura inilah tempat dilaksanakanya Upcara Pujawali dan Perang Topat yang Peneliti teliti.

Penelitian dilakukan secara langsung selama kurang lebih dua bulan, yakni pada bulan November sampai Desember 2015. Dalam kurun waktu tersebut telah dilakukan observasi awal, wawancara mendalam, dan observasi partisipan di lokasi penelitian.

Metode dan pendekatan yang digunakan dalam penelitian ini adalah metode deskriftif kualitatif dengan pendekatan etnografi. Denzin (1995: 25) menjelaskan "ethnography, then refers to social scientific description of people and cultural basis of the people-hood". Spadley (1997: 12) juga menambahkan bahwa etnografi adalah "sebuah bangunan pengetahuan yang meliputi metode penelitian, teori dan berbagai macam deskripsi kebudayaan".

Penelitian ini akan mengurai dan mendeskripsikan budaya Pujawali dan
Perang Topat darisudut pandang masyarakat pribumi, sehingga bisa memberikan pengetahuan yang menyeluruh tentang bagaimana data-data yang bebrupa artefak seperti benda-benda, simbol yang ada pada upacara tersebut dan juga data-data abstrak budaya seperti nilai, norma dan keyakinan yang terkonvergensi sehingga membentuk hubungan baik warga Muslim dan Hindu di Lingsar.

Secara keseluruhan penelitian ini melakukan wawancara pada 8 informan. Dari 8 informan tersebut pada pembahasan ini diantaranya 1 Pemangku dan 1 stake holder beserta 6 masyarakat Muslim dan Hindu, yang peneliti anggap sampel yang mengetahui informasi.

Terkait sampel, penelitian ini menggunakan purposive sampling untuk mendapatkan data yang akurat. Sehingga penelitian memperkuat teknik sampling dengan menggunakan snowball sampling. Menurut Patton (2002: 237) "chain sampling. This is an approach for locating informationrich key informants or critical cases.... Those people or events recommended as valuable by a number of different informants take on special importance. The chain of recommended informants will typi-cally diverge initially as many as possible sources are recommended, then converge as a few key names get mentioned over and over".

Metode kualitatif deskriptif, pendekatan etnografi, dan purposive sampling yang peneliti gunakan dalam penelitian ini, dinilai sudah tepat untuk mendeskripsikan terbentuknya hubungan Muslim dan Hindu dalam upacara budaya Pujawali dan Perang Topat di Lingsar.

\section{LANDASAN TEORITIK}

\section{Sekat Antara Muslim dan Hindu dalam Komunikasi Antarbudaya}

Cultural distance is also large when people have difference social structure, such as family structures. Todd (1983) dalam Samovar dan Porter (2003:18). Jarak budaya akan semakin melebar ketika 
seseorang memiliki perbedaan struktur sosial. Perkembangan kehidupan sosialnya, manusia semakin hari semakin banyak. Di tahun 2015 saja terdapat 7 miliar jiwa lebih manusia yang menghuni bumi dan tidak ada yang sama. Manusia bisa berbeda warna kulit, menggunakan pakaian yang berbeda dan memiliki pemikiran atau ide yang berbeda pula. Banyak dari kita yang mempercayai satu Tuhan dan yang lain mempercayai banyak Tuhan. Inilah contoh saking mudahnya melihat orang-orang dari keberagaman budaya mereka satu sama lain termasuk warga Muslim dan Hindu.

Warga Muslim dan Hindu yang melakukan upacara Pujawali dan Perang Topat tentu saja memiliki perbedaan, perbedan yang paling mendasar adalah agama. Quraish Shihab dalam Nata (2011: 5) mengatakan Manusia di dunia telahir dengan fitrah (potensi beragama), sehingga bapak dan ibunya yang menjadikanya beragama Islam, Kristen, Hindu, dan Budha. Kehidupan agama sangat penting bagi manusia karena agama mengajarkan tentang nilai kemanusiaan, kebaikan, dan jalan hidup yang senantiasa membimbing manusia kearah yang lebih baik (Harahap, 2011: 16).

Agama sendiri berasal dari kata "a" yang berarti "tidak", dan "gama" yang berarti "kacau". Maksudnya, orang-orang yang memeluk suatu agama dan mengamalkan ajaran-ajarannya, hidupnya tidak akan kacau. Dalam bahasa arab agama sering sebut din yang mengandung arti menguasai, patuh, utang, menundukan, balasan, dan kebiasaan. Adapun yang lain, makna agama adalah religi yang berasal dari kata relegare yang berarti mengikat. Menurut Elizabet K. Nottingham dalam (Nata, 2011: 9-11) agama adalah usaha-usaha manusia untuk mengukur makna dari keberadaannya sendiri dan keberadaan alam semesta.

Agama juga dikatakan sebagai candu rakyat (religion is the opium of the people) yang merupakan teks Karl Marx yang paling terkenal (Mufid, 2010: 51). Hal ini menujukkan penyalahgunaan agama yang digunakan oleh orang-orang yang beragama untuk kepentingan dan egoismenya sendiri.

Agama tentu saja menjadi sebuah sumber yang sangat besar bagi perbedaan sudut pandang. Sebuah agama misalnya saja Muslim dan Hindu saat mengetahui orang lain meyakini atau mempercayai hal yang berbeda. Hal ini akan menjadikan dasar bagi mereka untuk menilai yang bersifat menghakimi. Tidak hanya itu, unsur-unsur budaya (agama) tersebut disebutkan oleh Ross (dalam Judith dan Nakayama, 2010) berpotensi menghadirkan ketegangan dialektis antara agama yang berbeda misalnya Muslim dan Hindu.

Senada dengan hal tersebut Samovar, Porter, dan McDaniel (2009) menjelaskan bahwa bukan hanya agama tetapi dalam sebuah budaya terdapat lima unsur budaya, yaitu: sejarah, agama, nilai-nilai, organisasi sosial, dan bahasa. Maka ketika dasar-dasar ini dipegang dengan kuat oleh masyarakat Muslim dan Hindu yang tentunya memiliki perbedaan yang cukup jauh misalnya mereka berintraksi dalam upacara Pujawali dan Perang Topat maka akan menimbulkan sekat (barriers) komunikasi antara budaya.

Chaney dan Martin (2004) mengungkapkan bahwa communication barrier atau sekat komunikasi adalah segala sesuatu yang menjadi penghalang untuk terjadinya komunikasi yang efektif. Sehingga integrasi yang dilakukan oleh warga Muslim dan Hindu melalui komunikasi antarbudaya dilakuakan dalam Upacara Pujawali dan Perang Topat terhalang oleh hal tersebut.

Hal-hal yang menjadi penghalang dalam komunikasi warga Muslim dan Hindu pada upacara Pujawali Dan Perang Topat telah dijabarkan oleh LaRay M. Barna dalam (Jandt, 1998: 50) "has developed a list of six such barriers: anxienty, assuming similiarity instead of difference, ethnocentrism, stereotypes and prejudice, nonverbal ministerpretation, and language. His catagories of barriers will be used when discussing problem of ritual of Pujawali and Perang Topat, that can arise in intercultural encounters". 
Barriers komunikasi antar budaya antara Muslim dan Hindu yang paling penting dalam upacara Pujawali dan Perang Topat adalah stereotypes and prejudice serta ethnocentrism. Hal-hal tersebulah yang menjadi penghalang paling besar yang melatarbelakangi interaksi pada saat upacara tersebut.

Jandt (1998: 70-71) menjelasakan stereotypes and prejudice are a pernicious stumbling block to intercultural communications. The term stereotype is the boarder term commonly used to refer to negative or positive judgments made about individuals based on any observable or believed group membership, whereas prejudice refers to the irrational suspicious or hatred of a particular group, race, religion or sexual orientation. The term are related in that they both refer to making judgments about individuals based on group.

Pertama, Stereotip merupakan hasil persepsi yang sangat berbahaya dalam komunikasi antar budaya. Stereotip ini kontraproduktif ketika menempatkan orangorang pada kelompok yang salah. Saat stereotip buruk yang tidak bertanggung jawab dilekatkan pada budaya lain dan dikomunikasikan pada seluruh anggota budaya maka akan memunculkan persepsi buruk terhadap kelompok budaya lainnya tersebut secara komunal. Psychologists have attempted to explain stereotyping as mistakes our brain make in the perceptions of the other people that are smilar to those mistakes our brain make in the perception of visual illusions (Nisbett,1980)

Pengalaman pribadi dan subyektifitas pun dapat menjadi bahan stereotip dengan sangat mudah menyebar, terlebih ketika stereotip tersebut diproduksi oleh masyarakatyang sangat mudah terpengaruh dalam kelompok sosial-budaya. Distorsi budaya dan fakta mengenai budaya lain akan menjadi alat yang sangat efektif dalam menanamkan kebencian. Sebab, membawa nama budaya berarti sudah melabelkan stereotip tersebut pada seluruh anggota budaya.
Kedua, yang juga berbahaya adalah buruk sangka. Buruk sangka merupakan prasangka negatif yang timbul pada kelompok atau kebudayaan tertentu. Prasangka ini dapat muncul secara tibatiba yang akan mengakibatkan kemarahan, kebencian, dan permusuhan.

Perbedaan budaya, baikyang mencakup jenis kelamin, usia, agama, dan lainnya tidak luput dari prasangka ini. Ruscher dalam Samovar, Porter, \& McDaniel (2009: 117) mengatakan bahwa dalam ilmu komunikasi, perasaan buruk ini biasa dilakukan oleh orang-orang melalui pelabelan kelompok, humor atau lelucon, dan pidato atau pernyataan atas keunggulan kelompoknya dibandingkan dengan kelompok yang lain.

Akhirnya prasangka ini menimbulkan kebenciaan yang tidak berdasar yang menjadi sekat komunikasi antar warga Muslim dan Hindu. Jika kebencian ini berlaku secara masif, pelabelan buruk terhadap budaya yang dibenci secara turun-temurun akan sangat mungkin terjadi. Yang paling riskan adalah ketika prasangka ini digunakan secara sengaja untuk kepentingan suatu kelompok agama agar menjadi budaya yang superior dari budayabudaya yang lain.

Terakhir, etnosentrisme adalah pandangan yang mengagungkan budaya dan etnis sendiri. Kebanggan terhadap identitas budaya tersebut seringkali berujung pada sikap merendahkan budaya dan etnis orang lain. Hal ini dilakukan dengan cara membandingkan satu budaya dengan budaya lainnya "is judging other cultures by comparison with one's own" Gidden (dalam Purwasito, 2015: 233). Etnosentris pun akhirnya memiliki potensi dalam melahirkan sekat komunikasi antar budaya bagi warga Muslim dan Hindu.

Semakin etnosentris kedua kelompok tersebut, makayang akan ditimbulkan adalah kecemasan saat keduanya berinteraksi. Masing-masing kelompok menginginkan adanya keuntungan dari komunikasi yang dilakukan, dan kurang bersedia untuk mempercayai kelompok lainnya. 
Etnosentrisme di atas pada akhirnya memunculkan manipulasi informasi. Ketidakpercayaan dalam komunikasi dapat dijelaskan oleh Burgon, et. al, dengan tahapan berikut: Pertama, Burgoon, et. al (dalam McCornack, et. al., 1996) menganggap bahwa penerima yang stategis menggunakan berbagai dimensi informasi. Ada bukti kuat bahwa individu tidak memproses isyarat pesan dengan waspada dan berpendidikan. Kedua, informasi yang diungkapkan dalam pesan yang menipu secara substansial berbeda dari informasi yang benar, yakni perbedaan yang akan mengakibatkan penerima berinisiatif mendeteksi ulang pesan yang diterima. Ketiga, ketika penerima pesan mendeteksi adanya manipulasi informasi, mereka akan beranggapan telah diperdaya oleh komunikator dari kelompok lain sehingga mungkin ini menjadi barriers komunikasi antar budaya yang akan sulit diselesaikan.

\section{HASIL DAN PEMBAHASAN}

\section{Perbedaan Keyakinan Antara Warga Muslim dan Hindu}

Masyarakat Muslim dan Hindu sangat bertentangan sekali dengan masalah keyakinan yang dianut, hal ini didasarkan atas ajaran-ajaran agama yang dilandasi nash kitab-kitab suci yang dimiliki oleh masing-masing agama. Prinsip dasar semua agama mengajarkan kebaikan terhadap sesama tetapi yang membedakan adalah konsep ketuhanan yang diajarakan oleh kitab-kitab tersebut.

Konsep ketuhanan yang dianut oleh warga Muslim adalah mereka percaya bahwa Tuhan itu satu atau Esa yang disebut dengan tauhid. Tauhid adalah inti dari seluruh tata nilai dan norma agama Islam yang diyakini oleh warga Muslim yang ada di Lingsar. Hal ini didasarkan atas ayat AlQur'an diantaranya surah :

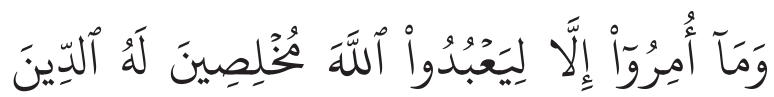

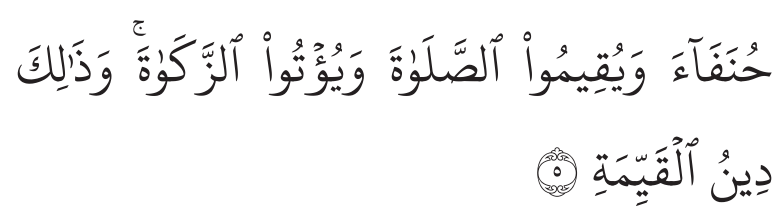

Padahal mereka tidak disuruh kecuali supaya menyembah Allah dengan memurnikan ketaatan kepada-Nya dalam (menjalankan) agama yang lurus[Lurus berarti jauh dari syirik (mempersekutukan Allah) dan jauh dari kesesatan], dan supaya mereka mendirikan shalat dan menunaikan zakat; dan yang demikian Itulah agama yang lurus. (Q.S. Al Bayyinah : 5).

Kata hunafaaa'a berarti memurnikan ketauhidan kepada Allah tanpa menyekutukan-Nya dengan benda ciptaanNya, sehingga menyekutukan Tuhan dianggap tabu dan sirik oleh masyarakat Muslim yang ada di Lingsar. Perilaku sirik dipercaya tabu oleh masyarakat Lingsar dikarenakan sebagai dosa yang sangat besar yang tidak terampuni oleh Tuhan, selain itu sirik juga akan membuat segala amalan gugur dan tidak diterima oleh Tuhan.

Perilaku sirik juga dianggap tabu dikarenakan hal tersebut telah melecehkan agama Islam yang telah dianut oleh masyarakat Muslim di Lingsar, sehingga hal tersebut dapat menjadi pergunjingan yang meresahkan masyarakat. Dari hasil observasi langsung, Peneliti menemukan ada beberapa warga Muslim yang ada di Lingsar resah dan menganggap upacara yang dilangsungkan secara bersama dengan warga Hindu termasuk prilaku musrik.

"Kita akan berusaha untuk mengembalikan dan meluruskan kearah syariat yang benar, secara pelan-pelan dan bertahap kita akan memberitahu mereka". (Pak Adil, pada 21. 12. 2015 di Lingsar Barat).

Keyakinan warga Hindu sangat berbeda dengan keyakinan yang dianut oleh Muslim dengan masalah ketuhanan, meskipun menurut agama Hindu Tuhan adalah Esa (eka), Maha Kuasa, Maha Ada, dan menjadi 
sumber dari segala yang ada dan tiada. Kepercayaan atas kesatuan ini dapat dilihat dari rumusan-rumusan mantra (ayat) yang terdapat dalam kitab "Reg Weda".

Tetapi dalam teologi Hindu juga dijumpai banyak jumlah dan nama DewaDewa. Menurut hasil penelitian Max Muller, jumlah Dewa-Dewa sebanyak 33 dewa dan terbagi atas 3 kelompok yang terdiri dari 11 dewa untuk tiap wilayah kekuasan dunia, angkasa, dan surga. Hal ini terdapat dalam kitab Reg Weda dan Atharvaveda. Kutipan dari Reg Weda terjemahan Pudja dan Sadia (1981) yang menjelaskan jumlah dewadewa berikut adalah :

Ye devaso divvy ekadasa stha prthivyam adhy

Ekdasa stha, apsuksito mahinaikadoja stha

Te devaso yajnamimam jusadhvam

Artinya :"wahai para dewa (33 dewa), sebelas di surga, sebelas di bumi dan sebelas di langit, semoga engkau bersuka cita dengan persembahan suci ini".

Jumlah 33 Dewa tersebut mempunyai fungsi masing-masing dalam hubungannya dengan kehidupan manusia. Dewa-Dewa tersebut dipandang sebagai manifestasi Tuhan. Observasi langsung yang dilakukan Peneliti saat upacara Pujawali dan Perang Topat di lokasi upacara Pura Gadoh dan Kemaliq ditemukan banyak sekali patung Dewa, batu (petima), dan kelengkapan upacara yang menjadi manifestasi Tuhan.

Warga Muslim dari sana mempersepsi negatif ajaran agama Hindu yaitu menganggap ajaran tersebut tidak benar sehingga efek yang ditimbulkan adalah merasa benar dan saling menyalahkan. Menurut Chaney dan Martin (2004), "hambatan komunikasi yang dilatar belakangi oleh persepsi muncul karena setiap orang memiliki persepsi yang berbeda-beda akan suatu hal, sehingga dalam mengartikan sesuatu setiap budaya akan memiliki persepsi yang berbedabeda".
Prasangka warga Muslim tentang kepercayaan warga Hindu yang tidak sesuai dengan keyakinan mereka, itulah membuat warga Muslim memvonis agamanya lebih baik daripada agama Hindu. Sehingga warga Muslim membatasi diri dalam ritualritual yang dilakukan oleh warga Hindu pada saat upacara Pujawali dan Perang Topat. "is judging other cultures by comparison with one's own" Gidden dalam (Purwasito, 2015: 233)

Memanifestasikan Tuhan oleh warga Hindu ini dianggap sebagai bentuk penyekutuan Tuhan oleh warga Muslim, sehingga warga Muslim dalam upacara Pujawali dan Perang Topat tidak mengikuti segala pendoaan yang dilakukan oleh warga Hindu karena dianggap bertentangan.

"Kita tidak mengikuti peribadahan mereka, karena Tuhan kita berbeda dengan mereka. Kita hanya bersamasama dalam adat saja, habbluminalloh kita berbeda tapi hablumminannas kira bersama" (Mangku Parman, pada 21. 12. 2015 di Gubuk Jero).

Dari pernyataan di atas, Muslim membatasi diri dengan Hindu dalam upacara-upacarayangmenyangkutmasalah ketuhanan karena sangat bertentangan sekali dengan masalah hukum agama yang diyakini oleh penganut agama Islam. Warga Muslim juga menganggap upacara Pujawali dan Perang Topat hanya sebuah ritual adat berbeda dengan warga Hindu yang menjadikan Pujawali dan Perang Topat selain ritual adat sekaligus mereka anggap upacara tersebut sebagai ritual agama.

\section{Prasangka Negatif}

Rasa sama-sama memiliki terkadang sering menjadi sebuah boomerang yang dapat menimbulkan persepsi negatif antar warga Muslim dan Hindu sehingga membuat sekat komunikasi antar kedua belah pihak, komunikasi yang berlangsung dipengaruhi kecurigaan-kecurigaan didasarkan keberhakan yang berlebihan dari rasa memiliki yang kuat. 
Keberhakan ini muncul disebabkan lokasi yang dianggap keramat dan suci tempat berlangsungnya upacara Pujawali dan Perang Topat merupakan hak dari masing-masing mereka. Masyarakat Muslim dan Hindu saling mengklaim lokasi tersebut merupakan warisan yang diturunkan oleh nenek moyang mereka, sehingga mereka merasa paling berhak untuk bertanggungjawab, menjaga, dan memiliki lokasi tersebut.

Lokasi tersebut adalah taman Lingsar yang di dalamnya terdapat Pura Gadoh dan Kemaliq sebagai tempat berlangsungnya upacara Pujawali dan Perang Topat. Warga Muslim menganggap tempat tersebut sebagai lokasi sakral dan suci karena Kemaliq merupakan tonggak awal munculnya Islam di wilayah Lingsar.

"Tanak Kemaliq lek taman Lingsar no laek luas gati, tanak ne lek mbe-mbe. Dengan sasak epene, dengan bali cume ye tembeng nyodok doang"(tanah Kemaliq itu dulunya luas sekali, tanahnya dimana-mana. Yang punya itu orang sasak, orang Bali Cuma dikasi nempatin saja) (Wirtadi, pada 21. 12. 2015 di Lingsar Timur).

Warga Hindu mempersepsikan hal yang berbeda dengan warga Muslim. Pura di Lingsar adalah tempat yang suci bagi agama Hindu, hal ini dikarenakan Pura sebagai khyangan tempat turunnya Dewa sekaligus tempat peribadahan yang hanya dimiliki oleh umat Hindu saja.

"Pura Lingsar dibangun oleh anak agung untuk peribadatan orang-orang Hindu" (I komang wenten, pada 11. 1. 2016 di Narmada).

"Sebenarne ite tejajah laek sik anak agung, jari selapuk tanak tekuasain sik anak agung"(sebenarnya kita dijajah dulu Anak Agung, jadi semua tanah di kuasai oleh Anak Agung) (Amaqku/ Mangku Parman, pada 21. 12. 2015 di Gubuk Jero).

Keuangan Taman Lingsar juga menjadi masalah utama yang paling sering menjadi pembicaraan, masyarakat Muslim yang ada di Lingsar ketika berbicara selalu mempertanyakan transparansi keuangan Taman Lingsar yang berasal dari hasil bumi, kunjungan turis, dan bantuan dari Pemerintah kepada anggota kelompoknya.

"Kebon manggis sik galuh bedoen Kemaliq, kance tanak pecatu,sekali panen no pire maukne, laguk ndek wah bae merue, trus sai aning kepeng ne? kan dengan bali kelola ye....(luas sekali padahal kebun manggisnya Kemaliq dan tanah pecatunya, sekali panen berapa yang dia dapat tapi kok tidak nampak hasinya, terus kesiapa uang hasil tersebut? kan orang Bali yang mengelolanya). (Wirtadi, pada 21. 12. 2015 di Lingsar Timur).

"Kalo dilihat taman Lingsar begitubegitu saja kelihatanya, tidak bisa maju. padahal kalo dilihat kunjungan turis berapa yang datang tiap hari, lain dari pemerintah." (Suparman, pada 14. 1. 2016 di MTs NW Lingsar).

Dari percakapan di atas, terlihat ketidakpuasan warga Muslim terhadap warga Hindu yang menimbulkan ketidaksukaan, hal tersebut juga menyebabkan warga Muslim merasa enggan untuk berkomunikasi langsung dengan warga Hindu. Keengganan membuat masyarakat Muslim tidak dapat mengklarifikasi informasi dari warga Hindu untuk mendapatkan kejelasan terhadap informasi tersebut, akibatnya kejelasan menjadi tidak ada dikarenakan warga Muslim membatasi diri dengan warga Hindu.

dan kepemimpinan Taman Lingsar menjadi masalah yang tidak kalah menambah ketidaksukaan warga Muslim terhadap Hindu. Hal ini menyebabkan ketidakpercayaan sehingga mejadikan dinding pemisah antar keduanya semakin kuat. Tindakan-tindakan warga Hindu yang tidak disukai oleh warga Muslim tersebut dilakukan warga Hindu tanpa mengkomunikasikan terlebih dahulu 
kepada pihak Muslim. Sehingga timbul prasangka dipihak Muslim yaitu Hindu ingin menguasai seluruh Taman Lingsar yang direstui oleh Pemimpin Kerama Pura tanpa memikirkan hak warga Muslim dengan tindakan tersebut.

"Dulu pada tahun 80an, di Kemaliq itu tidak ada berhala. Tidak boleh, tetapi pada awal 90an mulai ditaruh satu, satu dampai sekarang banyak patung. Seperti patung Garuda itu sebenarnya dulu gak ada. gak boleh" (Lalu Zohriawan, pada 20. 1. 2016 di Lingsar Timur).

"Di Pancor Siwaq dulu pernah ada pelang penunjuk yang dibuat Hindu bertulisakan "pancor siwa". Nah Siwa kan Dewa orang Hindu, berbeda dengan siwaq yang artinya Sembilan yang menyimbolkan Wali Songo. Lalu kami rusak Pelang itu." (Wawan, pada 11. 12. 2015 di Lingsar Lendang).

"Pas renopasi atap Bale di Kemaliq, atap yang dibuat oleh tukang yang di suruh oleh pimpinan kerama Pura membuat atap bersusun seperti Pura Bali, lalu bapak (Mangku Parman) memarahi dia dan disuruh membongkar ulang" (Wawan, pada 11. 12. 2015 di Lingsar Lendang).

Warga Muslim terprovokasi oleh tindakan-tindakan yang dilakukan oleh warga Hindu seperti itu, sehingga warga Muslim semakin tidak suka dan sempat melakukan perusakan karena di dalam pikiran masyarakat Muslim tercipta anggapan bahwa Hindu itu "licik" dan mempunyai niat yang tidak baik untuk menguasai Pura Lingsar dengan caracara yang tidak disukai. "Psychologists have attempted to explain stereotyping as mistakes our brain make in the perceptions of the other people that are smilar to those mistakes our brain make in the perception of visual illusions" (Nisbett,1980).

Peneliti juga menemukan terjadi konflik sosial sebelum upacara Pujawali dan Perang Topat. Konflik berupa pemukulan yang terjadi antara pemuda warga Muslim
Lingsar kepada pemuda Hindu desa Tragtag sekitar dua minggu sebelum upacara keseluruhan.

Pada tanggal 24 September 2015, Peneliti membaur dengan kelompok warga Hindu yang sedang bergotong-royong. Peneliti mendengar percakapan yang isinya mengenai pelaporan warga Muslim yang memukul warga Hindu kepada Polisi dan pelaku masih diburu oleh Polisi. Seorang dari warga Hindu yang bilang "buserbuser" ketika Peneliti duduk membaur dan percakapan kelompok Hindu berakhir.

Peneliti saat meminta izin penelitian ke Kantor Desa, surat penelitian yang Peneliti masukkan belum ditandatangani. Staf Desa Lingsar lalu memberitahukan kepada Peneliti bahwa Kepala Desa sedang ke Kecamatan untuk memediasi konflik pemukulan pemuda yang terjadi sebelum upacara Pujawali dan Perang Topat tersebut.

"Suratnya belum ditandatangani kepala desa sedang pergi, Kemana buk? ke Kecamatan urus mediasi dengan kepala Desa Trak-tag" (Stap Desa, pada 10. 12. 2015 di Kantor Desa Lingsar).

Barriers komunikasi antar budaya bukan cuma dari Muslim, tetapi warga Hindu dengan konflik tersebut menjadi sinis dengan warga Muslim. Hal ini disebabkan karena mereka menganggap warga Muslim melakukan kesewenang-wenangan dan kekerasan kepada salah satu bagian dari kelompok mereka. Sehingga kejadian inilah yang menambah sekat komunikasi antar budaya antara Muslim dan Hindu dalam upacara Pujawali dan Perang Topat.

Barriers komunikasi yang dipaparkan di atas merupakan sekat yang paling berpengaruh dalam komunikasi warga Muslim dan Hindu. Perbedaan kepercayaan, masalah kepemilikan Pura Lingsar, dan perkelahian pemuda dari oknum warga Muslim dan Hindu memicu disharmoni antara kedua agama tersebut. Hal ini tentu saja berimbas terhadap integrasi hubungan yang telah terbangun. 


\section{E. Simpulan}

Pada integrasi hubungan (Relationship) Muslim dan Hindu dalam upacara Pujawali dan Perang Topat di Lingsar tidak terlepas dari dinamika, ditemukan adanya masalah yang disebabkan oleh perasangka, etnosentris, dan stereotip sehingga menimbulkan barriers (sekat) komunikasi antar budaya yang menjadi dinamika dalam integrasi hubungan tersebut. Barriers yang membatasi Muslim dengan Hindu dalam upacara Pujawali dan Perang Topat adalah masalah ajaran agama. penganut agama Islam dan agama Hindu sangat bertentangan sekali dengan masalah hukum agama yang diyakini, terutama pada masalah ketuhanan yang menibulkan sekat di antara mereka.
Warga Muslim dan Hindu juga menganggap masing-masing dari mereka lebih berhak dari yang lain dalam mengurus Pura dan Kemaliq Lingsar, sehingga timbul prasangka Muslim terhadap Hindu tentang masalah keuangan, kepemimpinan, dan kebijakan pembangunan Pura yang dinilai merugikan mereka. Di sisi lain, warga Hindu menganggap warga Muslim melakukan kesewenang-wenangan dan kekerasan disebabkan kasus pemukulan yang terjadi sebelum upacara tersebut berlangsung. Inilah dinamika paling berpengaruh dalam menyekat komunikasi antar budaya Muslim dan Hindu di Lingsar

\section{DAFTAR PUSTAKA}

Chaney, Lilian, \& Martin, Jeanette. 2004. Intercultural Business Communication. New Jersey: Pearson Education, Inc, Upper Saddle River.

Denzin, Norman K. 1994. Hand Book Of Qualitatife Research. Thousand Oaks: SAGE Publications.

Depag RI. 1995. Al-Qur'an dan Terjemahannya, Semarang : PT. Karya Toha Putra.

Harahap, Syahrin. 2011. Teologi Kerukunan, Jakarta: Prenada Media.

Jandt, Fred. E. 1998. Intercultural Communication An Introductions, Thousand Oaks: Sage Publications.

Martin, N. Judith \& Nakayama, K. 2010. Intercultural Communication in Contexts: Fitfth Edition. New York: The McGraw-Hill Companies.

Mufid, Muhammad. 2010. Etika Dan Fisafat Komunikasi. Jakarta: Kencana.

McCornack, et. al. 1996. Speaking of Informatioan Manipulation: Acritical Rejonder. Communication Monographs. Vol. 63, P. 83-92.

Mustain dan Umam, Fawaizul. 2005. Pluralisme: pendidikan agama \& hubungan muslim hindu di Lombok. Mataram: LKM IAIN Mataram.

Nata, Abuddin. 2011. Metodologi Studi Islam. Jakarta: PT Raja Grafindo Persada.

Nisbet, R. E. 1980. Human Inference: Strategies and Shortcomings of Social Judgment. Englewood Cliffs, NJ: Prentice Hall.

Patton, Michael Quinn. 2002. Qualitative research and evaluation methods (3rd ed.). Thousand Oaks: SAGE Publications.

Porter, R. and Samovar, L. 2003. Intercultural communication: A reader (10th ed.), Belmont, California: Wadsworth.

Puja, G. dan W, Sadia. 1981. Reg Weda: Mandala I \& II, terjemahan departemen agama RI. Jakarta. 
Purwasito, Andrik. 2015. Komunikasi Multikultural. Pelajar Pustaka: Jogjakarta.

Samovar A Larry, Porter E. Richard, \& McDaniel R. Edwin. 2009. Communication Between Cultures. Boston: Wadsworth.

Spadley, James P. 1997. Metode etnografi. Penerjemah: Misbah Zulfa Elisabet. Tiara Wacana, Yogyakarta. 